\title{
Patient-reported outcomes of brentuximab vedotin in Hodgkin lymphoma and anaplastic large-cell lymphoma
}

\author{
Robert Chen' \\ Suzanne Allibone ${ }^{2}$ \\ Nancy L Bartlett ${ }^{3}$ \\ Pauline Brice ${ }^{4}$ \\ Andy Chen ${ }^{5}$ \\ Katrina Pose ${ }^{6}$ \\ Lynn Rich \\ Vijay Bonthapally ${ }^{8}$ \\ Phillip M Garfin' \\ Michelle Fanale ${ }^{10}$ \\ 'Department of Hematology \& \\ Hematopoietic Cell Transplantation, \\ City of Hope, Duarte, CA, USA; ${ }^{2}$ The \\ Lymphoma Service of the Christie \\ NHS Foundation Trust, Manchester, \\ UK; ${ }^{3}$ Department of Medical \\ Oncology, Washington University \\ School of Medicine, St Louis, MO, \\ USA; ${ }^{4}$ Department of Hemato- \\ Oncology, Hôpital Saint-Louis, Paris, \\ France; ${ }^{5}$ Knight Cancer Institute, \\ Oregon Health \& Science University, \\ Portland, OR, ' 6 Lymphoma and Cancer \\ Survivorship Stanford Comprehensive \\ Cancer Center, Stanford, CA, \\ ${ }^{7}$ Lymphoma Program, James P. Wilmot \\ Cancer Institute, University of \\ Rochester Medical Center, Rochester, \\ NY, ${ }^{8}$ Millennium Pharmaceuticals Inc., \\ Cambridge, MA, 'Seattle Genetics, \\ Inc., Bothell,WA, ${ }^{10}$ Department of \\ Lymphoma/Myeloma, The University \\ of Texas MD Anderson Cancer Center, \\ Houston, TX, USA
}

Correspondence: Robert Chen City of Hope, 1500 East Duarte Road, Duarte, CA 91010, USA

Tel + I 6263598 III

Email rchen@coh.org
This article was published in the following Dove Press journal:

OncoTargets and Therapy

6 April 2016

Number of times this article has been viewed

Background: Patients with relapsed/refractory (R/R) Hodgkin lymphoma (HL) or R/R systemic anaplastic large-cell lymphoma (sALCL) treated with brentuximab vedotin (BV) experienced high remission rates in two Phase II trials. With increased response rates and survival times, patientreported outcomes (PROs) and health-related quality of life (HRQoL) are becoming increasingly important and can help inform treatment decisions to enhance care of cancer patients.

Objective: The objective was to qualitatively assess HRQoL in long-term survivors treated with BV.

Methods: An eight-question survey assessing PRO-related aspects was developed and fielded to a subset of patients with HL or SALCL who remained in long-term follow-up after completing BV treatment in the two pivotal studies.

Results: The survey was completed by 25 of 38 patients ( 12 with HL, 13 with sALCL). The majority of patients reported that their energy level, outlook on life, difficulties with daily activities, ability to participate in physical activities, and overall HRQoL improved compared to those before BV treatment.

Limitations: Small sample size and lack of a baseline questionnaire or validated assessment instrument limit broad applicability of these findings to large populations of patients with HL or SALCL.

Conclusion: This is the first report of BV PRO data in R/R HL and SALCL. Given the patients' poor prognostic outcomes before stem cell transplant, these encouraging results warrant formal evaluation of PRO end points in BV trials.

Keywords: patient well-being, brentuximab vedotin, health-related quality of life, pilot study, activities of daily living

\section{Introduction}

Assessment of the long-term effects of cancer and its treatment is essential to patient care. ${ }^{1,2}$ Although overall survival and disease-free survival remain as key end points for randomized clinical trials in oncology, ${ }^{3}$ patient-reported outcomes (PROs) are increasingly used to inform treatment decisions and enhance quality of care. ${ }^{4}$ As a result, PRO assessments are incorporated more frequently into randomized controlled trials in oncology. ${ }^{5}$ PROs describe physical, emotional, functional, and psychosocial well-being and can provide help to assess the cumulative impact that cancer and its treatment have on patients. PRO data are also valuable to health care policy makers, regulatory organizations, and payers to help determine the worthiness of a therapy. For example, the US Food and Drug Administration has provided guidance on the incorporation and evaluation of PRO measures in clinical trials, and both the National 
Cancer Institute and American Cancer Society have stated goals to ensure improvement in quality of life (QoL) in patients with cancer and cancer survivors. ${ }^{6-8}$ Several research and policy efforts in the USA reflect the growing emphasis placed upon PROs in decision making surrounding the care of patients with cancer. ${ }^{2-4}$

Treatments for Hodgkin lymphoma (HL) and systemic anaplastic large-cell lymphoma (sALCL) can be effective and impart relatively high survival rates for those who experience one of these lymphomas; most patients with HL or sALCL have disease that responds to therapy, and they have a good chance of being cured by first-line multimodal therapy. ${ }^{9-11}$ Nevertheless, $15 \%-20 \%$ of patients with HL and $36 \%-60 \%$ of patients with sALCL fail first-line therapy and have relatively poor outcomes, particularly if relapsed prior to stem cell transplant (SCT), despite aggressive therapy. ${ }^{10-15}$

Owing to its uniform expression on malignant cells in $\mathrm{HL}$ and sALCL, CD30 has emerged as an attractive target for the treatment of these lymphomas. The antibody-drug conjugate brentuximab vedotin (BV) delivers the potent microtubuledisrupting agent monomethyl auristatin E to CD30-positive cells. ${ }^{14,15}$ Two pivotal Phase II multicenter, open-label trials evaluated the safety and efficacy of BV in patients with relapsed/refractory (R/R) HL (NCT00848926) or sALCL (NCT00866047). ${ }^{14,15}$ BV was associated with manageable toxicity and high objective response rates $(75 \% \mathrm{HL} ; 86 \%$ sALCL). ${ }^{14,15}$ The most common treatment-related adverse events $(>15 \%$ in either study) in both studies included peripheral sensory neuropathy, nausea, fatigue, pyrexia, diarrhea, and neutropenia. ${ }^{14,15}$

As the number of survivors of HL and SALCL continues to grow, it will be increasingly important to understand the long-term disease- and treatment-related effects on survivor QoL. To understand the impact that BV might have on the QoL of patients who have survived HL or sALCL, we developed a brief eight-question survey to collect patient reports of QoL in the posttreatment setting for R/R HL or sALCL. The survey was fielded to patients who continued to return for long-term follow-up visits following therapy on either of the two Phase II trials described previously. This publication, the first PRO survey in $\mathrm{R} / \mathrm{R}$ patients treated with $\mathrm{BV}$, reports the results and discusses the impact this type of information may have on long-term patient care.

\section{Methods}

\section{Participants}

Detailed methodology used in the two pivotal Phase II studies of BV as well as the demographic and clinical characteristics of the patients with R/R HL or sALCL have been previously published. ${ }^{14,15}$ Briefly, inclusion criterion for the sALCL trial included $\mathrm{R} / \mathrm{R}$ sALCL after treatment failure of $\geq 1$ prior therapy with curative intent and CD30-positive disease. ${ }^{14}$ Patients in the HL trial had to have R/R HL after high-dose chemotherapy and autologous stem cell transplantation (ASCT) and CD30-positive disease. ${ }^{15}$ Briefly, 102 and 58 patients were included in the R/R HL and sALCL trials, respectively. In the HL trial, $47 \%$ of patients were male, patients had a median age of 31 years (range: $15-77$ ), 71\% had primary refractory disease, patients had received a median of 3.5 prior chemotherapy regimens, and all patients underwent ASCT. ${ }^{15}$ Of the 58 patients in the sALCL study, $57 \%$ were male and had a median age of 52 years (range: 14-76), 62\% had primary refractory disease to front-line treatment, and patients had received a median of two prior lines of therapy. ${ }^{14}$ Patients in both studies were treated with BV at $1.8 \mathrm{mg} / \mathrm{kg}$ intravenously over 30 minutes every 3 weeks on an outpatient basis for up to 16 cycles. Clinical response was determined by both investigators and by an independent central review facility according to revised response criteria for malignant lymphoma. ${ }^{16}$

During the long-term follow-up period, all patients who received one or more dose of study drug were evaluated for survival and disease status every 3 months during years 1 and 2, every 6 months during years 3-5, and annually thereafter.

\section{Survey design and administration}

Seattle Genetics, Inc., designed a pilot survey to assess PROs and provided the survey to study sites that participated in the two Phase II trials described earlier. The survey consisted of a series of ranked, close-ended questions with the opportunity to provide additional details to support their responses (Table 1). Surveys were offered to patients who returned for long-term follow-up visits and consented to participate in the study. Surveys were completed during the clinic visit and/or at the patient's convenience. Results were compiled, analyzed, and interpreted by Seattle Genetics, Inc. Patients were allowed to complete the survey only once. The pilot survey was approved by each study site's Institutional Review Board or Ethics Committee, and all patients provided written informed consent.

\section{Results \\ Patients}

Surveys were fielded to 38 patients who met the criteria for long-term follow-up. Long-term follow-up was defined as the time to earliest progressive disease per investigator assessment, death, or last contact. Twenty-five patients 
Table I Patient questionnaire

I. Have you had an SCT following completing treatment in the brentuximab vedotin clinical study? Yes/No

a. If yes, allogeneic or autologous

i. If allogeneic, are you currently experiencing any GVHD complications? Yes/No.

If yes, please describe

2. Are you working (includes working at home, childcare, volunteering, etc)? Yes/No a. If yes, full time or part time

3. Are you a student? Yes/No. If yes, full time or part time

4. Currently my energy level is (circle one)

Great compared to before/Good compared to before/About the same as I was before/Worse than I was before

5. My general outlook on life is (circle one)

Very positive compared to before/Positive compared to before/About the same as I was before/Negative compared to before

6. Do you have any issues or difficulties with your activities of daily living compared to your level of activity previously? Yes/No. If yes, please

describe. (Please limit to 100 words or less.)

7. Are you able to participate in physical activities (ie, regular exercise, running, biking, walking)? Yes/No

8. How is your life today compared to prior coming on to the brentuximab vedotin clinical trial (please limit to 100 words or less)?

Notes: For questions 4-8 the following instructions was provided. "Your response to the following questions should be your perception of how your status is now compared to that before your clinical trial therapy with brentuximab vedotin".

Abbreviations: GVHD, graft-versus-host disease; SCT, stem cell transplant.

(66\%) completed the survey (12/19 from the HL study and 13/19 from the sALCL study). Demographic information and clinical characteristics of patients who completed the survey are presented in Table 2 . The median age of the survey respondents was 41 years ( 27 years HL; 53 years sALCL). At the initiation of treatment with BV, participants had an Eastern Cooperative Oncology Group performance status of $0(40 \%)$ or $1(60 \%)$. The most common stage at diagnosis was stage II for patients with HL (75\%) and stage IV for patients with sALCL (46\%). At baseline, $36 \%$ of participants had baseline B symptoms, fever and night sweats being the most common symptoms.

The median follow-up from the first dose of BV for all study participants was $\sim 5$ years $(60.2$ months; range: 37.7-66.5; Table 2). Clinical benefits as assessed per investigator and according to the responding population are listed in Table 3. The overall objective response rate of the survey participants was $100 \%(92 \%$ complete remission and $8 \%$ partial remission). The median duration of response has not been achieved (range: $>9.9$ months to $>64.7$ months). No patients have died since completing the survey, and only one participant from the sALCL study had subsequent progressive disease.

\section{Survey responses}

Of the survey participants, 13 (52\%) responded that they had undergone an SCT after treatment with BV. Of the patients who specified the type of SCT they received $(n=12)$, seven had an allogeneic SCT (four patients with HL and three with sALCL) and five patients (all sALCL) reported receiving an autologous SCT. For those receiving allogeneic SCT, five participants (three patients with HL and two with sALCL) reported experiencing graft-versus-host disease (GVHD) complications, including mouth and leg sores, scleroderma, worsened diabetes, shortness of breath, diarrhea, skin allergies, and rosacea.

More than half (56\%) of all respondents reported that they were currently working or going to school $(66 \% \mathrm{HL}$ and $46 \%$ sALCL); the proportion of survey responders who reported not working or going to school had a higher mean age (33 vs 52 years old, respectively). Of all study participants who were able to work, eight and four participants reported working full time and part time, respectively. When examined by study, five and two participants with HL reported working full time and part time, respectively, and three and two participants with SALCL reported working full time and part time, respectively.

The majority of survey participants from both studies $(17 / 25 ; 68 \%)$ reported that their energy level was good or great compared with before the treatment with BV (Figure 1A); the majority of participants in the HL study $(10 / 12 ; 83 \%)$ responded that their energy level was good or great compared with before the treatment with $\mathrm{BV}$, and seven of 13 participants (54\%) of the sALCL study responded similarly. The six remaining patients from the sALCL study $(6 / 13 ; 46 \%)$ responded that their energy level was about the same or worse compared with that before the treatment with BV. One patient with SALCL reported an energy level worse than prior to BV treatment due to GVHD complications.

All survey respondents reported that their general outlook was the same or improved compared to their outlook before starting treatment with BV (Figure 1B). Most patients (20/25 [80\%]) reported having a positive or more positive outlook 
Table 2 Survey respondent demographics and disease characteristics

\begin{tabular}{|c|c|c|c|}
\hline Characteristic & HL study $(n=12)$ & sALCL study $(n=13)$ & All patients $(\mathrm{N}=25)$ \\
\hline Median age, years & 27.0 & 53.0 & 41.0 \\
\hline Min, $\max$ & 21,63 & 14,76 & 14,76 \\
\hline \multicolumn{4}{|l|}{ Sex, n (\%) } \\
\hline Male & $5(42)$ & $9(69)$ & $14(56)$ \\
\hline Female & $7(58)$ & $4(31)$ & II (44) \\
\hline \multicolumn{4}{|l|}{ Race, n (\%) } \\
\hline Asian & $\mathrm{I}(8)$ & 0 & I (4) \\
\hline Black or African American & 0 & $2(15)$ & $2(8)$ \\
\hline White & II (92) & II (85) & $22(88)$ \\
\hline \multicolumn{4}{|l|}{ Ethnicity, n (\%) } \\
\hline Hispanic or Latino & $2(17)$ & $3(23)$ & $5(20)$ \\
\hline Not Hispanic or Latino & $10(83)$ & $10(77)$ & $20(80)$ \\
\hline \multicolumn{4}{|l|}{ ECOG performance status, $\mathrm{n}(\%)$} \\
\hline 0 & $6(50)$ & $4(3 I)$ & $10(40)$ \\
\hline 1 & $6(50)$ & $9(69)$ & $15(60)$ \\
\hline \multicolumn{4}{|l|}{ ALK status, $\mathrm{n}(\%)$} \\
\hline Positive & NA & $3(23)$ & $3(12)$ \\
\hline Negative & NA & $10(77)$ & $10(40)$ \\
\hline \multicolumn{4}{|c|}{ Time from initial diagnosis to first dose, months } \\
\hline Mean (STD) & $47.76(26.90)$ & $34.18(35.24)$ & $40.70(31.63)$ \\
\hline Median & 37.24 & 22.93 & 31.74 \\
\hline Min, $\max$ & II.8, 98.7 & $5.2,113.2$ & $5.2,113.2$ \\
\hline Baseline B symptoms, $\mathrm{n}(\%)$ & $3(25)$ & $6(46)$ & $9(36)$ \\
\hline Fever & I (8) & $4(31)$ & $5(20)$ \\
\hline Night sweat & $2(17)$ & $3(23)$ & $5(20)$ \\
\hline Weight loss $>10 \%$ & I (8) & 0 & I (4) \\
\hline \multicolumn{4}{|c|}{ Follow-up time from first dose, months } \\
\hline Mean (STD) & $62.30(3.28)$ & $56.31(7.05)$ & $59.18(6.25)$ \\
\hline Median & 62.93 & 58.05 & 60.16 \\
\hline Min, $\max$ & $56.1,66.0$ & $37.7,66.5$ & $37.7,66.5$ \\
\hline \multicolumn{4}{|c|}{ Follow-up time from EOT, months ${ }^{a}$} \\
\hline Mean (STD) & $53.26(4.18)$ & $48.80(9.24)$ & $50.42(7.64)$ \\
\hline Median & 53.49 & 46.42 & 52.30 \\
\hline Min, $\max$ & $44.8,59.6$ & $25.2,61.4$ & $25.2,61.4$ \\
\hline
\end{tabular}

Notes: ${ }^{\text {aEOT }}$ visit date or last dose +30 days. Excludes patients with progressive disease before EOT.

Abbreviations: ALK, anaplastic lymphoma kinase; ECOG, Eastern Cooperative Oncology Group; EOT, end of treatment; HL, Hodgkin lymphoma; Min, minimum; Max, maximum; sALCL, systemic anaplastic large-cell lymphoma; STD, standard deviation.

Table 3 A summary of clinical responses of respondents per investigator

\begin{tabular}{|c|c|c|c|}
\hline End point, $\mathrm{n}(\%)$ & HL study $(n=\mid 2)$ & sALCL study $(n=13)$ & Both studies $(\mathbf{N}=\mathbf{2 5})$ \\
\hline \multicolumn{4}{|l|}{ Best clinical response } \\
\hline Complete remission, $\left[95 \% \mathrm{Cl}^{2}\right]$ & 10 (83), [51.6-97.9] & $13(100),[75.3-100]$ & 23 (92), [74-99] \\
\hline Partial remission & $2(17)$ & 0 & $2(8)$ \\
\hline Stable disease & 0 & 0 & 0 \\
\hline Progressive disease & 0 & 0 & 0 \\
\hline Objective response rate $(\mathrm{CR}+\mathrm{PR}),\left[95 \% \mathrm{Cl}^{2}\right]$ & $12(100),[73.5-100]$ & $13(100),[75.3-100]$ & 25 (100), [86.3-100] \\
\hline Number of patients with subsequent PD or death & 0 & I (8) & I (4) \\
\hline Disease control rate (CR + PR + SD), $\left[95 \% \mathrm{Cl}^{2}\right]$ & $12(100),[73.5-100]$ & $13(100),[75.3-100]$ & $25(100),[86.3-100]$ \\
\hline
\end{tabular}

Notes: The duration of response was calculated from the earliest occurrence of either CR or PR. a Computed using the method of Brookmeyer and Crowley.

Abbreviations: $\mathrm{Cl}$, confidence interval; $\mathrm{CR}$, complete remission; $\mathrm{HL}$, Hodgkin lymphoma; PD, progressive disease; PR, partial remission; sALCL, systemic anaplastic largecell lymphoma; SD, stable disease. 

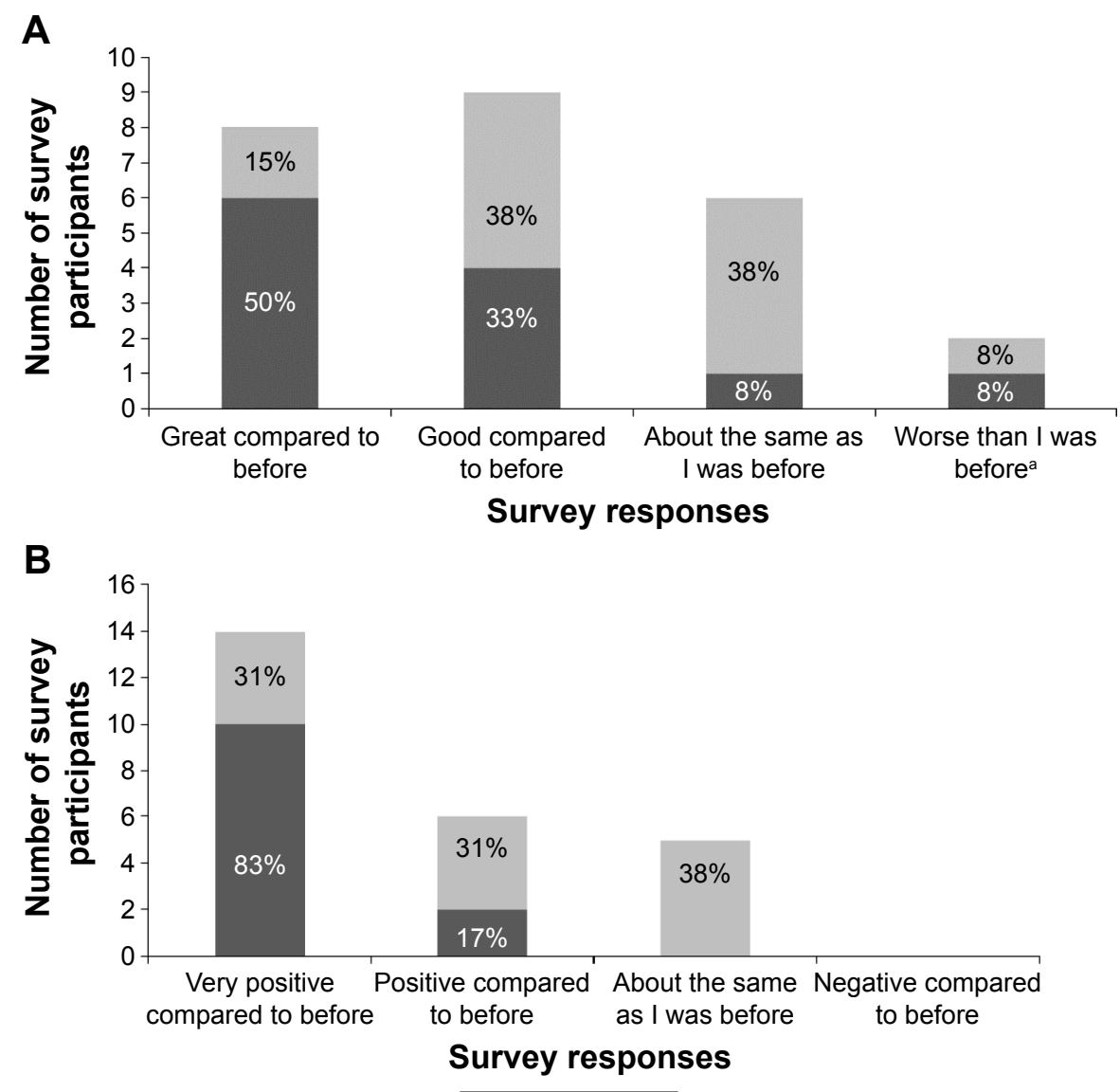

$\mathrm{HL} \quad \mathrm{sALCL}$

Figure I (A) Current energy level compared with that before the treatment with BV. (B) Current general outlook on life compared with that before the treatment with BV.

Note: aBoth patients had graft-versus-host disease.

Abbreviations: BV, brentuximab vedotin; HL, Hodgkin lymphoma; sALCL, systemic anaplastic large-cell lymphoma.

on life (12 and eight participants from the HL study and the sALCL study, respectively), and $20 \%$ of participants (5/25), all with sALCL, reported that their general outlook was about the same as before the start of BV treatment.

Most of the patients who responded to the survey $(22 / 25$ [88\%]) were able to participate in daily activities, and the majority $(72 \%)$ reported no new issues or difficulties with activities of daily living compared with their previous level of activity. A few patients (6/25 [24\%]; two from the HL study and four from the sALCL study) reported new issues with activities of daily life including numbness in toes (from neuropathy) sometimes affecting balance but not QoL, increased requirement for sleep including daytime sleep to stay active, leg pain and swelling from blood clot, flare in rheumatoid arthritis that hinders energy and function involving hands and feet, leg cramps, and impaired mobility hindering use of stairs.

In response to the survey question, "How is life today, compared to before coming on the BV clinical trial?", all patients with HL responded relatively positive (Table 4). Participants in the sALCL study had a mixed, but mostly positive, set of responses.

\section{Discussion}

$\mathrm{BV}$ is an important treatment option for patients with relapsed HL or sALCL who would otherwise have had limited therapeutic options and an unfavorable prognosis. The improved responses reported in key BV clinical trials ${ }^{14,15,17}$ warrant consideration of health-related QoL (HRQoL) in the posttreatment setting as an important factor in maintaining patient treatment satisfaction and well-being. The prognosis for patients experiencing relapse is poor, and the QoL of patients who live with HL or sALCL is often compromised. ${ }^{18,19}$ Therefore, it is critical for decision makers to evaluate both treatment outcomes and QoL. This is the first report of PRO data from a pilot survey of patients with R/R HL or sALCL treated with $\mathrm{BV}$, the results of which provide encouraging insights into patient well-being after receiving BV therapy for 
Table 4 Examples of responses to the question "How is life today, compared to prior to coming on the BV clinical trial?"

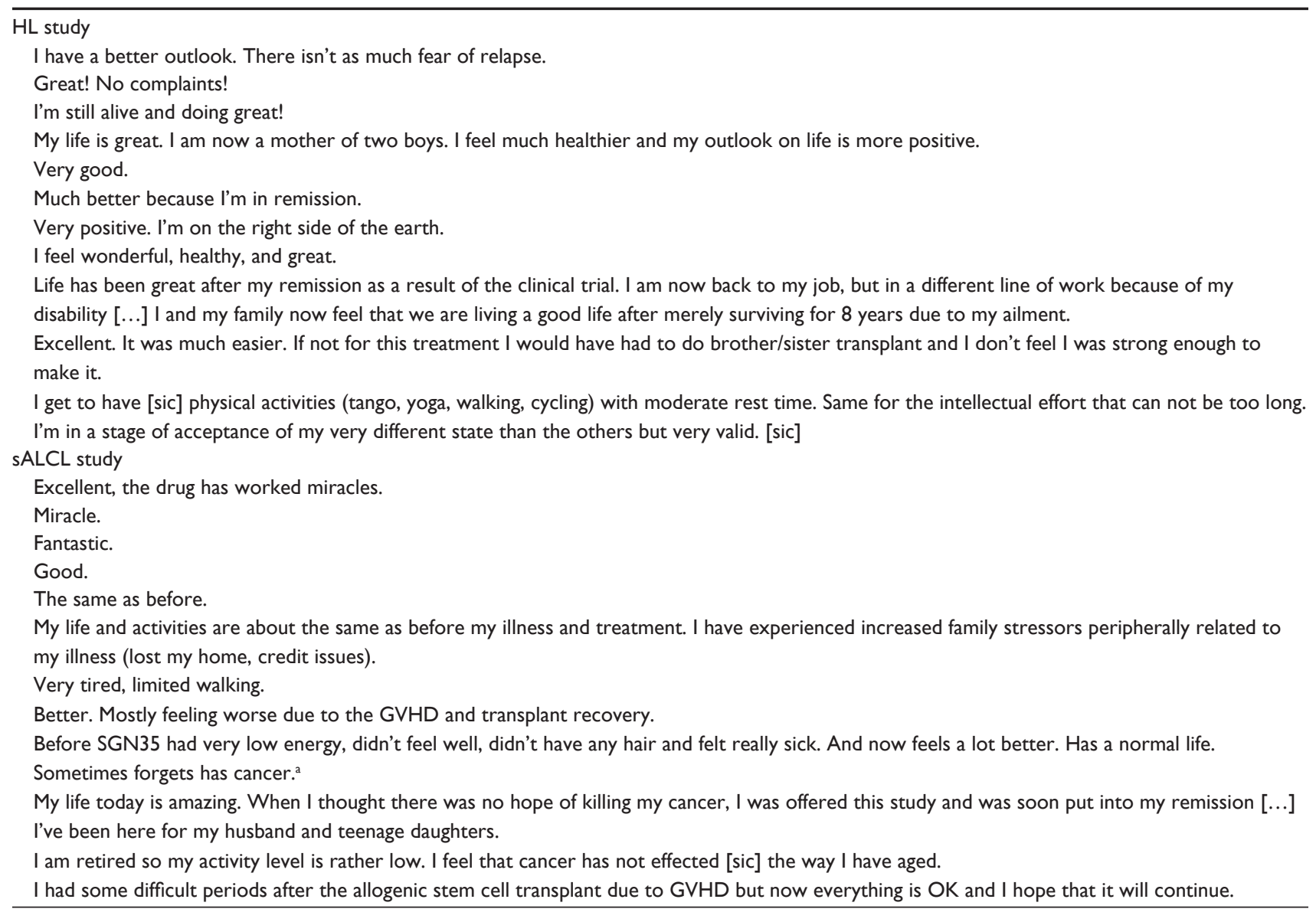

Note: aResponse entered on behalf of patient by evaluating physician.

Abbreviations: HL, Hodgkin lymphoma; GVHD, graft-versus-host disease; sALCL, systemic anaplastic large-cell lymphoma.

$\mathrm{R} / \mathrm{R}$ HL or SALCL in the posttreatment setting. The majority of patients reported good or great energy levels and improved outlook on life, and the majority were working or attending school and able to participate in activities of daily living. Notably, five of the seven patients who underwent SCT also responded positively to the survey questions.

The symptoms of cancer and adverse events associated with its treatments can greatly impact patient QoL and the well-being of long-term survivors, and patients can still suffer from somatic and psychological concerns months or years into recovery. ${ }^{18-20} \mathrm{HL}$ is one of the more common cancers in young adults. ${ }^{11}$ These patients can have many years of life ahead of them, and thus maximizing HRQoL for the survivors of this cancer should be an important goal as we evaluate new therapies for HL. Additionally, as survival rates increase with the advancement of therapies for HL or sALCL, the margin of improvement in survival provided by any new therapy will decrease. Thus, understanding the impact of novel therapies - as single agents or in combination with established regimens - on HRQoL may drive clinical decision making and changes to standards of care.

PRO data not only provide insight into patient well-being after therapy and are essential for the evaluation of cancer care, ${ }^{21,22}$ but their importance is also reflected in the abundance of guidance for developing, assessing, implementing, and analyzing such data from regulatory agencies, publishing standards organizations, quality standards organizations, and professional associations. ${ }^{2-5}$ PRO data are also important for payers and health technology assessments to understand the benefits and risks of treatments. However, the variety of satisfaction questionnaires used for patients with cancer has made comparisons and integration of results across studies challenging. ${ }^{22}$ This highlights the need for a common set of PRO instruments across studies for guiding clinical practice and informing health policy.

The current pilot study has several limitations, including a small sample size, lack of a baseline questionnaire for comparisons, use of a nonvalidated assessment instrument, and patient recall bias over a median of 5 years from the 
first dose of BV. Furthermore, patients in the long-term follow-up, to whom the pilot survey was offered, may be expected to report more positive outcomes by virtue of having no or minimal disease. Conversely, some patients who underwent an SCT may report a less-positive outlook and less energy due to symptoms associated with GVHD. Notably, five of the seven patients who received an SCT responded positively to the survey questions; the remaining two patients who reported negatively on energy levels before and after treatment experienced GVHD. Lastly, although therapy subsequent to BV could impact PROs, at the time the questionnaire was provided, patients had not received any other therapy other than SCT.

\section{Conclusion}

Despite the limitations of this study, the results showed that patients treated with BV self-reported positive QoL are leading their lives with few limitations to daily functioning, emotional well-being, and work life. These findings underscore the need to more formally characterize PROs with BV using validated instruments given the improvements in response and survival in these highly refractory patients and the promising signal reported herein. Selecting the most appropriate PRO tool(s) in ongoing and future BV trials will help guide physicians, caregivers, and patients through treatment and survivorship. Furthermore, the assessment of HRQoL with validated PRO instruments in future trials may help determine the value of BV in earlier lines of therapy, when current standards are effective at treating illness, but often at the expense of creating long-term complications of therapy.

\section{Acknowledgments}

The authors would like to thank Dana A Kennedy and Eric Sievers (Seattle Genetics, Inc.) for their contributions to the study design and conduct, and Yinghui Wang (Seattle Genetics, Inc.) for statistical guidance. Medical editorial assistance was provided by Tara Ruest and Ann Yeung (Scientific Pathways) with funding from Seattle Genetics, Inc. Direct funding for this research was provided by Seattle Genetics, Inc., through the joint financial support of Seattle Genetics and Millennium Pharmaceuticals, Inc., a wholly owned subsidiary of Takeda Pharmaceutical Company Limited.

\section{Disclosure}

$\mathrm{RC}$, SA, NLB, AC, KP, and MF report receiving grants and/or consultant fees from Seattle Genetics or Takeda, Inc. outside this submitted work; AC and PB report receiving research support for the trials evaluated in this manuscript; VB and PMG are salaried employees of Millennium Pharmaceuticals, Inc., and Seattle Genetics, Inc, respectively. The authors report no other conflicts of interest in this work.

\section{References}

1. DeSantis CE, Lin CC, Mariotto AB, et al. Cancer treatment and survivorship statistics, 2014. CA Cancer J Clin. 2014;64(4):252-271.

2. National Comprehensive Cancer Network [webpage on the Internet] Clinical Practice Guidelines in Oncology: Survivorship. Version 1.2015. Fort Washington, PA: National Comprehensive Cancer Network. Available from: http:/www.nccn.org/professionals/physician_gls/pdf/ survivorship.pdf. Accessed April 24, 2015.

3. Lipscomb J, Gotay CC, Snyder CF. Patient-reported outcomes in cancer: a review of recent research and policy initiatives. CA Cancer J Clin. 2007;57(5):278-300.

4. Basch E. New frontiers in patient-reported outcomes: adverse event reporting, comparative effectiveness, and quality assessment. Annu Rev Med. 2014;65:307-317.

5. Efficace F, Rees J, Fayers P, et al; European Organization for Research and Treatment of Cancer (EORTC) Quality of Life Group. Overcoming barriers to the implementation of patient-reported outcomes in cancer clinical trials: the PROMOTION Registry. Health Qual Life Outcomes. 2014; $12: 86$.

6. US Food and Drug Administration [webpage on the Internet]. Guidance for Industry: Patient-Reported Outcome Measures: Use in Medical Product Development to Support Labeling Claims. Silver Spring, MD: US Food and Drug Administration. Available from: http:/www.fda. gov/downloads/drugs/guidancecomplianceregulatoryinformation/ guidances/ucm193282.pdf. Accessed April 22, 2015.

7. Clauser SB, Ganz PA, Lipscomb J, Reeve BB. Patient-reported outcomes assessment in cancer trials: evaluating and enhancing the payoff to decision making. J Clin Oncol. 2007;25(32):5049-5050.

8. American Cancer Society [webpage on the Internet]. Survivorship and Quality of Life Research. Atlanta, GA: American Cancer Society. Available from: http://www.cancer.org/research/survivaltreatmentresearch/ cancer-survivorship-grants. Accessed April 22, 2015.

9. Jaffe ES, Harris NL, Stein H, Vardiman JW. Anaplastic large cell lymphoma. In: Jaffe ES, Harris NL, Stein H, Vardiman JW, et al., editors. Pathology and Genetics: Tumors of Haematopoietic and Lymphoid Tissues. Lyon: IARC Press; 2001:230-235.

10. Macalalad AR, McAuliffe M, Yang H, et al. The epidemiology and targeted therapies for relapsed and refractory CD30+ lymphomas. Curr Med Res Opin. 2015;31(3):537-545.

11. Surveillance, Epidemiology and End Results Program [webpage on the Internet]. SEER Stat Fact Sheets: Hodgkin Lymphoma. Bethesda, MD: National Institutes of Health. Available from: http://seer.cancer. gov/statfacts/html/hodg.html. Accessed April 10, 2015.

12. Schirrmann T, Steinwand M, Wezler X, Ten Haaf A, Tur MK, Barth S CD30 as a therapeutic target for lymphoma. BioDrugs. 2014;28(2): 181-209.

13. Rancea M, Monsef I, von Treckow B, Engert A, Skoetz N. Highdose chemotherapy followed by autologous stem cell transplantation for patients with relapsed/refractory Hodgkin lymphoma. Cochrane Database Syst Rev. 2013;6:1-39.

14. Pro B, Advani R, Brice P, et al. Brentuximab vedotin (SGN-35) in patients with relapsed or refractory systemic anaplastic large-cell lymphoma: results of a phase II study. J Clin Oncol. 2012;30(18): 2190-2196.

15. Younes A, Gopal AK, Smith SE, et al. Results of a pivotal phase II study of brentuximab vedotin for patients with relapsed or refractory Hodgkin's lymphoma. J Clin Oncol. 2012;30(18):2183-2189.

16. Cheson BD, Pfistner B, Juweid ME, et al; International Harmonization Project on Lymphoma. Revised response criteria for malignant lymphoma. J Clin Oncol. 2007;25(5):579-586. 
17. Gopal AK, Chen R, Smith SE, et al. Durable remissions in a pivotal phase 2 study of brentuximab vedotin in relapsed or refractory Hodgkin lymphoma. Blood. 2015;125:1236-1243.

18. Daniëls LA, Oerlemans S, Krol AD, Creutzberg CL, van de PollFranse LV. Chronic fatigue in Hodgkin lymphoma survivors and associations with anxiety, depression and comorbidity. Br JCancer. 2014;110(4): $868-874$.

19. Flechtner H, Bottomley A. Fatigue and quality of life: lessons from the real world. Oncologist. 2003;8(suppl 1):5-9.

20. Ayanian JZ, Zaslavsky AM, Arora NK, et al. Patients' experiences with care for lung cancer and colorectal cancer: findings from the Cancer Care Outcomes Research and Surveillance Consortium. J Clin Oncol. 2010;28(27):4154-4161.
21. Hassett MJ, McNiff KK, Dicker AP, et al. High-priority topics for cancer quality measure development: results of the 2012 American Society of Clinical Oncology Collaborative Cancer Measure Summit. J Oncol Pract. 2014;10(3):e160-e166.

22. Lis CG, Rodeghier M, Gupta D. Distribution and determinants of patient satisfaction in oncology: a review of the literature. Patient Prefer Adherence. 2009;3:287-304.

\section{Publish your work in this journal}

OncoTargets and Therapy is an international, peer-reviewed, open access journal focusing on the pathological basis of all cancers, potential targets for therapy and treatment protocols employed to improve the management of cancer patients. The journal also focuses on the impact of management programs and new therapeutic agents and protocols on

\section{Dovepress}

patient perspectives such as quality of life, adherence and satisfaction. The manuscript management system is completely online and includes a very quick and fair peer-review system, which is all easy to use. Visit http://www.dovepress.com/testimonials.php to read real quotes from published authors. 